\title{
Conflicts Between Managerial and Medical Authorities and Their Impacts on Hospitals: Applied Study on Aljouf HospitalsAljouf Hospitals
}

\author{
Bander Khalid Al Rayes ${ }^{1 *}$ \\ ${ }^{1}$ Ministry of Health, Kingdom of Saudi Arabia \\ *Corresponding author: Bander Khalid Al Rayes, Ministry of Health, Kingdom of Saudi Arabia. \\ To Cite This Article: Bander Khalid Al Rayes. Conflicts Between Managerial and Medical Authorities and Their Impacts on Hospitals: Applied Study \\ on Aljouf Hospitals. Am J Biomed Sci \& Res. 2019 - 5(5). AJBSR.MS.ID.000958. DOI: 10.34297/AJBSR.2019.05.000958.
}

Received: 啙 September 26, 2019; Published: 眥 October 16, 2019

\begin{abstract}
Introduction: Health setting, in general, and hospitals in particular have complicated structure and culture and several types of employees, heads, departments accompanied by various layers of authorities including mainly medical authority and managerial authority.

Study objectives: The main objectives of the present study were to explore the extent of organizational conflict between medical and managerial authorities in hospitals, and to identify the impact of roles of physicians as managers on the performance of medical staff in hospitals.

\section{Methods and subjects}

Study design and setting: Across-sectional design was conducted to collect data from

participants (535) in health settings in Al-Jouf area of Saudi Arabia. A questionnaire was constructed for this study by researcher. Convenient sampling technique was used in this study. The analysis of data was carried out using SPSS version 21. Significance was considered at $\alpha \leq 0.05$.

Study findings: Slightly less than half of participants were management staff; health practitioners were slightly higher than one quarter of participants (about 26\%), and the proportion of visitors was about $23 \%$. About $75 \%$ of participants reported that health management specialists as the best for hospital management, while doctors were perceived to be the best for hospital management by less than a quarter of participants. Job nature was associated significantly with hospital management $(\mathrm{p}<0.05)$.
\end{abstract}

Conclusion: The results showed that the majority of participants prefer specialists in health managements to lead hospitals, but physicians were not highly preferred to occupy the positions of hospital managers.

Keywords: Conflicts; Management; Hospitals; Performance; Authority; Medical authority; Managerial authority

\section{Introduction}

\section{Conflicts at workplace}

Although teamwork in organizations is proposed to be the norm, but considerable challenges are expected to exist among teamwork. Conflict is a major challenge that may due to the tension between team members as a result of real or perceived differences [1]. However, to deliver healthcare with high quality it is required that various professional groups to work as teams, to share information, and to agree on different work aspects. Unfortunately, not all groups accept to However, not all groups of healthcare professionals collaborate effectively as teams due to conflict. This is expected to cause medical errors and adverse effects for patients [2]. Employees in hospitals have various cultural and religious backgrounds with various values and beliefs which makes conflict expected and unavoidable as they are working as teams, and accordingly the approach followed to manage such conflicts may impact quality care either negatively or positively [3].

Positive impacts of conflict management lead to increase the efficacy of professional know how, which is expected to increase quality care. On the other hand, the negative aspects of conflict management can be visualized as dysfunctional relationships within the team members accompanied with little to no concern about patient care [4]. Furthermore, the positive impact of conflict management has been described to improve teamwork by opinion sharing and increased discussions which, in turn, enhances decision making and performance as a result [5]. It is crucial for successful management of conflict that team members can be separated from 
their emotions and personality from their conflict. It has been observed that with time these emotions become out of control which implies that positive effects of conflict management are not lasting. On the other hand, poor conflict management is expected to make suffers for the whole health care organization as reflected by poor communication among team members and poor quality of patient care [4].

Because conflict is an unavoidable issue in healthcare, and the delivery of quality care relies on the contributions of multiple teams, conflict cannot only impede team function, but also decrease team effectiveness, and impact patient care [6]. Nurses usually are the most affected as they are the final line of treatment administration. Hence, this study seeks to understand the factors causing the development of conflict, the appropriate methods for conflict resolution which can enhance team performance, thus, increasing quality of patient care [4]. Conflicts are likely to occur in any organization due to the interactions between people working together [7]. Based on the principles of the theory of human relations, the occurrence of conflict among groups is natural part of human interaction [8]. However, conflict in an organization, as a term, has attracted the attention of numerous researchers $[7,9]$.

It is believed that conflicts may emerge if the requirements of an organization may lead to conflict in terms of the opinions, attitudes, values, and beliefs of the person [10]. It has been indicated that there is a possibility to develop conflict if different people in an organization are interacting with others who have conflicting expectations [8]. Hospital environment is characterized by its heterogeneity that requires collaboration among various departments and people to satisfy the goals of health setting in terms of both clinical and managerial objectives [11-13]. It is thought that the most important reasons leading to conflicts are unclear description of business-related functions as well as confused roles $[8,14,15]$. However, it has been indicated that both confusion and ambiguity regarding roles and responsibilities to be a known phenomenon facing health professionals (HPs) due to the nature of health profession that is not predictable, complex, and involves job contradicting issues [15].

Managers and management system find it is not an easy mission to deal with conflicts at workplace, and accordingly, it is considered a good managerial and leadership trait within the personality of the manager $[12,16,17]$. It is very important to identify conflicts at an early stage not to influence their solutions, and it is also proposed that leaders and managers to play an important role in finding conflicts once they occur [18]. It has been put on emphasis to determine behaviors, in particular that may help employees to control or to cope with conflicts $[8,19]$.

\section{Study objectives}

The main objectives of the present study were to explore the extent of organizational conflict between medical and managerial authorities in hospitals, to identify the impact of roles of physicians as managers on the performance of medical staff in hospitals, to investigate the acceptance level of medical and managerial staff for the physician role as a manager of the hospital, to clarify positive and negative aspects for the role of physician as a manager, to investigate the mistakes resulting from being the physician as a manager, to determine the appropriate qualifications for hospital manager, and if physician needs training courses for hospital management.

\section{Methods and Subjects}

\section{Study design}

The present study was based on cross-sectional design that permits collection of data from all participants within the same time frame.

\section{Study setting}

The present study was conducted in health settings in Al-Jouf area of Saudi Arabia.

\section{Study sample}

Study sample included 535 participants. The researcher distributed 745 questionnaires to study participants. The rate of response is: $535 / 745 \times 100=71.81 \%$.

\section{Study instrument}

The researcher developed a special questionnaire for this study after returning to studies in literature.

The questionnaire consisted of the following questions:

What is your work nature?

How many experience years you have?

Who do you think the best to manage hospitals?

What is/are the reason/s for your choice/s?

If the physician is the best to manage a hospital, do you think that heshould take courses in hospital management?

What is the optimal degree for hospital management?

What do you recommend to solve organizational conflicts between management authority and medical authority in hospitals?

The questionnaire was prepared in Arabic language to be easily understood and clearly answered.

\section{Statistical analysis}

The analysis of data was carried out using Statistical Package for the Social Sciences (SPSS) version 21. Descriptive statistics were used to describe data such as frequencies and percentages. Figures were also used to make clear presentation of data. The relationship between study variables was examined using Chi-Square analysis. Significance was considered at $\alpha \leq 0.05$. 


\section{Study findings}

\section{General characteristics of participants: As illustrated in (Table} 1, Figures 1\&2), the frequency

of participants by jobs showed that slightly less than half of participants were management staff; health practitioners were slightly higher than one quarter of participants (about 26\%), and the proportion of visitors was about $23 \%$. Slightly higher than the half of the participants reported having experience less than 10 years, whereas 10 years- experience was reported by quarter of participants. About $19 \%$ of participants reported having more than 10 years of experience.

\begin{tabular}{|c|c|c|}
\hline \multicolumn{3}{|c|}{ Table 1: General characteristics of participants } \\
\hline Variable & Frequency & Percentage \\
\hline Job: & & \\
Management staff & 257 & $48 \%$ \\
Health practitioner & 141 & $26.4 \%$ \\
Visitor & 121 & $22.6 \%$ \\
Missing & 16 & $3 \%$ \\
\hline Experience years: & & \\
<10 years & 274 & $51.2 \%$ \\
10 years & 134 & $25 \%$ \\
>10 years & 103 & $19.3 \%$ \\
Missing & 24 & $4.5 \%$ \\
\hline
\end{tabular}
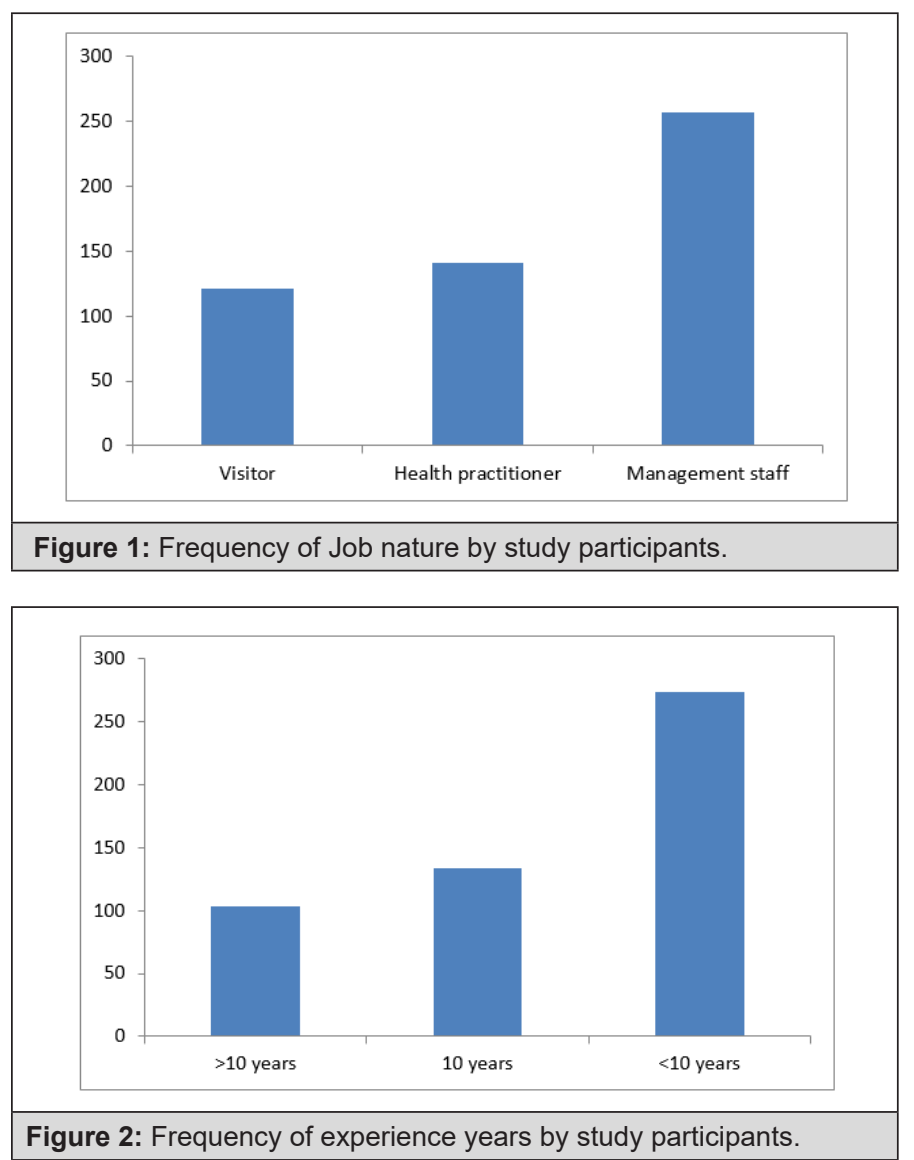

\section{Hospital management related variables: The participants were asked about their opinions}

regarding the best for hospital management. About three quarters of participants reported that health management specialists as the best, while doctors were perceived to be the best for hospital management by less than a quarter of participants. The reasons beyond the choices were: treatment flexibility (about $42 \%$ ), knowledge of disease and treatment (9\%), quality of provided services (8\%), knowledge of management systems (about $15 \%$ ), whereas about $27 \%$ of participants did not respond to this question. About $89 \%$ of participants who reported their perception that doctor as the best for hospital management believed that doctors should take training workshops and courses in hospital management. About half of participants thought that the best qualifications for hospital manager is the $\mathrm{Ph}$. D, followed by master degree (33.1\%), or bachelor degree (17\%) (Table 2).

Table 2: Hospital management related variables.

\begin{tabular}{|c|c|c|}
\hline Variable & $\begin{array}{c}\text { Frequency } \\
\text { (N) }\end{array}$ & $\begin{array}{c}\text { Percentage } \\
\text { (\%) }\end{array}$ \\
\hline The best for hospital management: & & \\
Health management specialist & 484 & $76.22 \%$ \\
Doctors & 148 & $23.31 \%$ \\
Missing & 3 & $0.47 \%$ \\
\hline Choice reasons: & 223 & \\
Treatment flexibility & 48 & $91.7 \%$ \\
Knowledge of disease and treatment & 43 & $8 \%$ \\
Quality of provided services & 78 & $14.6 \%$ \\
Knowledge of management systems & 143 & $26.7 \%$ \\
Missing system & & \\
\hline If doctor is the most appropriate & & \\
for hospital management, training & & \\
courses: & 475 & $88.8 \%$ \\
Yes & 47 & $8.8 \%$ \\
No & 13 & $2.4 \%$ \\
\hline Missing & & \\
Best qualification of hospital manager: & & $79 \%$ \\
- Bachelor & 51 & $0.9 \%$ \\
Master & & \\
PhD & & \\
\hline
\end{tabular}

The impact of job nature on hospital management variables: As seen in (Table 3), One Way

Anova test was used to examine the impacts of participant characteristics on hospital management variables. Job nature was associated significantly with hospital management variables $(\mathrm{p}<0.05)$. 


\begin{tabular}{|c|c|c|c|c|c|c|}
\hline & & Sum of Squares & df & Mean Square & $\mathbf{F}$ & Sig. \\
\hline \multirow{3}{*}{$\begin{array}{l}\text { Best for hospital } \\
\text { management }\end{array}$} & Between Groups & 2.501 & 2 & 1.25 & 3.789 & 0.023 \\
\hline & Within Groups & 169.288 & 513 & 0.33 & & \\
\hline & Total & 171.789 & 515 & & & \\
\hline \multirow{3}{*}{ Reason for choice } & Between Groups & 42.458 & 2 & 21.229 & 15.624 & 0 \\
\hline & Within Groups & 510.893 & 376 & 1.359 & & \\
\hline & Total & 553.351 & 378 & & & \\
\hline \multirow{3}{*}{ If doctor } & Between Groups & 0.801 & 2 & 0.401 & 3.754 & 0.024 \\
\hline & Within Groups & 54.967 & 515 & 0.107 & & \\
\hline & Total & 55.768 & 517 & & & \\
\hline \multirow{3}{*}{ Best qualification } & Between Groups & 7.807 & 2 & 3.903 & 6.995 & 0.001 \\
\hline & Within Groups & 285.135 & 511 & 0.558 & & \\
\hline & Total & 292.942 & 513 & & & \\
\hline
\end{tabular}

The impact of experience years on hospital management variables: As demonstrated in

\begin{tabular}{|c|c|c|c|c|c|c|}
\hline & & Sum of Squares & df & Mean Square & $\mathbf{F}$ & Sig. \\
\hline \multirow{3}{*}{ Best for hospital management } & Between Groups & 0.216 & 2 & 0.108 & 0.323 & 0.724 \\
\hline & Within Groups & 168.971 & 505 & 0.335 & & \\
\hline & Total & 169.187 & 507 & & & \\
\hline \multirow{3}{*}{ Reason for choice } & Between Groups & 11.127 & 2 & 5.563 & 3.835 & 0.022 \\
\hline & Within Groups & 535.325 & 369 & 1.451 & & \\
\hline & Total & 546.452 & 371 & & & \\
\hline \multirow{3}{*}{ If doctor } & Between Groups & 0.075 & 2 & 0.037 & 0.355 & 0.701 \\
\hline & Within Groups & 53.384 & 507 & 0.105 & & \\
\hline & Total & 53.459 & 509 & & & \\
\hline \multirow{3}{*}{ Best qualification } & Between Groups & 3.923 & 2 & 1.962 & 3.476 & 0.032 \\
\hline & Within Groups & 283.849 & 503 & 0.564 & & \\
\hline & Total & 287.773 & 505 & & & \\
\hline
\end{tabular}

(Table 4). Experience years were not associated significantly with the variable "best for hospital management" ( $p=0.724)$, and the variable "if doctor" ( $\mathrm{P}=0.701)$. On the other hand, experience years were significantly associated with the variables "reasons for choice" ( $p=0.022)$, and "best qualification" ( $p=0.032)$.

\section{Discussion}

Hospital management is a renewable administrative and leadership issue as hospitals have a heterogeneous society of individuals, including doctors, nurses, administrators, maintenance workers, and others. The ultimate goal of these human gatherings is to provide patient medical service. Therefore, hospital management must follow the latest administrative and leadership styles. In local and regional health circles, a doctor is usually the head of health care setting, whether in hospitals or health centers. Perhaps the doctor is not administratively qualified to effectively manage the hospital, and there may be a conflict between the administrative and medical authorities in the hospital, which leads to negative repercussions on the performance of staff and the safety of patients. The findings of the present study showed that slightly less than half of participants were management staff, and about a quarter of participants were health practitioners, while the remaining proportion was due to visitors.

Actually this represents the complicated structure of hospitals which implies that one mode of management or leadership cannot be optimal to satisfy the needs and demands of different types of employees. These findings are consistent with previous studies $[20,21]$. The study answered the question "Is each doctor suitable for the management of the hospital?" About three quarters of participants reported that the best for hospital management is health management specialist, and slightly less than one quarter of participants reported doctors as the best for hospital management. Several studies across the literature clearly indicated that there is a need to include what is called clinical leadership to cope with leadership needs and management demands of the hospitals. These 
studies are in consistency with our results and confirm the need of qualified personnel for hospital management, rather than doctors [20,22-25]. These studies have put focus on qualifying persons to be good leaders including doctors.

The participants in general perceived doctors to be in hospital management mainly due to medical aspects such as treatment flexibility (42\%), knowledge of disease and treatment (9\%), while about $22 \%$ for reasons related to management aspects. It was surprising that about $27 \%$ of participants did not answer this question which reflects not clarity of the situation. It is plausible to explain these findings through the classical roles of doctors as hospital managers, as a classical topic. In other words, participants lack the exposure of having other persons to be hospital managers rather than doctors. This is in line with previous studies that reported the need for qualified persons in the top management positions [20,22-25]. Regarding the question "What are the most important qualities that must be available in the director of the hospital?" About half of participants thought that Ph. D holders should manage hospitals, followed by Master degree, or Bachelor degree. This is interestingly reflecting good awareness status.

However, it is now recognized that hospital management is responsible for other roles like gaining the approval and accreditation by accrediting sites. This shifted the concept from classical views of management into what is known as Total Quality Management (TMQ). Engagement of TQM requires effective hospital leadership and management, which, in turn, requires putting the best quality of individuals in the appropriate places [26-29]. We investigated the impact of job nature on hospital management variables using One Way Anova. According to significance level, job nature was associated significantly with "reason for choice" $(\mathrm{p}=0.000)$, "best qualification" $(\mathrm{p}=0.001)$, "best for hospital management" ( $p=0.023)$, and "if doctor" $(p=0.024)$. The main jobs included were either administrative or medical jobs.

In accordance with previous tables, we found that about $50 \%$ of reasons to choose hospital managers as doctors were due to sufficient medical knowledge, while best qualifications were mainly for Ph. D holders. In other words, job of nature was in favor for knowledge and high education level. This may indicate that the participants of this study would prefer doctors with educational level to be preferred to manage hospitals. To be more specific, most doctors, specialist ones have clinical degrees including board, or fellowships rather than $\mathrm{Ph}$. D. This leads us to explain this by taking into consideration that other health professionals who hold $\mathrm{Ph}$. $\mathrm{D}$ are more preferable to manage hospitals as perceived by study participants. However, these findings agree with other studies such as $[8,30,31]$. The study findings showed that "experience of years" was significantly associated with two variables "reasons for choice" $(\mathrm{p}=0.022)$, and "best qualification" ( $\mathrm{p}=0.032)$.

We think that experience of years can be expressed as more experience in life and accordingly participants may increase their awareness and expand their cognition and reached their decisions accordingly. Both variables may reflect the maturity of employees as a matter of time. Other studies have indicated that with more experienced years, the perceptions are changed, and employees become positive and mature towards their organization, and tend to have less conflicts [8,32,33].

\section{Conclusion}

The results showed that the majority of participants prefer specialists in health managements to lead hospitals, but physicians were not highly preferred to occupy the positions of hospital managers.

\section{References}

1. Claris Shakanyuy Yufenyuy (2018) The Impact of Interprofessional Conflict on Quality care - The Nurse's Role. Degree thesis, Arcada University of Applied Sciences.

2. Vathsala J, Sepali G, Bawantha G, Sherry E (2016) Interprofessional work in operating rooms: a qualitative study from Sri Lanka. BMC Surg 16(1): 61.

3. Patton CM (2014) Conflict in Health Care: A Literature Review. The Internet Journal of Healthcare Administration 9: 1.

4. Higazee M Zeinhom A (2015) Types and levels of conflicts experienced by nurses in the hospital settings. Health Science Journal.

5. Janss R, Rispens S, Segers M, Jehn K (2012) What is happening under the surface? Power, conflict, and the performance of medical team. Med Educ 46(9): 838-849.

6. Brown J, Lewis L, Ellis K, Stewart M, Freeman T, et al. (2011) Conflict on Interprofessional Primary Healthcare Teams, can it be resolved. J Interprof Care 25(1): 4-10.

7. Rovithis M, Linardakis M, Rikos N, Merkouris A, Patiraki E, et al. (2017) Role conflict and ambiguity among physicians and nurses in the public health care sector in Crete. Archives of Hellenic Medicine 34(5): 648655.

8. Pitsillidou M, Farmakas A, Noula M, Roupa Z (2018) Conflict management among health professionals in hospitals of Cyprus. J Nurs Manag 26(8): 953-960.

9. Giannikas A (2014) Foundations of effective strategies for conflict in the educational environment, with emphasis on decision-making and the education officials advisory role. Erkina 3: 136-147.

10. Erdenk N, Altuntas S (2017) Do personality traits of nurses have an effect on conflict management strategies. J Nurs Manag 25(5): 366-374.

11. Papadopoulou D (2014) Conflicts of nursing personnel in health services. Scientific Chronicles 19(4): 332-344.

12. Al Hamdan Z, Nussera H, Masa'deh R (2016) Conflict management style of Jordanian nurse managers and its relationship to staff nurses' intent to stay. J Nurs Manag 24(2): E137-E145.

13. McKibben L (2017) Conflict management: Importance and implications. Br J Nurs 26(2): 100-103.

14. Bonner A, Walker A (2004) Nephrology nursing: Blurring the boundaries: The reality of expert practice. J Clin Nurs,13(2): 210-218.

15. Haraway DL, Haraway WM (2005) Analysis of the effect of conflictmanagement and resolution training on employee stress at a healthcare organization. Hosp Topi: 83(4): 11-17.

16. Nayeri ND, Negarandeh R (2009) Conflict among Iranian hospital nurses: A qualitative study. Hum Resour Health 7: 25.

17. Papadopoulou D (2015) Methods of organizational conflict management. Scientific Chronicles 20(2): 107-119. 
18. Villi M, Galani CA, Bogiatzoglou N (2010) The conflict between the members of an organization for the prevention of conflict and the development of functionality within an organization. Paper presented at the Pan-Hellenic Conference for Health and Work Safety, Athens Pp. 29-30.

19. Tidd ST, Friedman RA (2002) Conflict style and coping with role conflict: An extension of the uncertainty model of work stress. International Journal of Conflict Management 13(3): 236-257.

20. Braithwaite J, Westbrook M (2005) Rethinking clinical organizational structures: an attitude survey of doctors, nurses and allied health staff in clinical directorates. J Health Serv Res Policy 10(1): 10-17.

21. Kearin M, Johnston J, Leonard J, Duffield C (2007) The impact of hospital structure and restructuring on the nursing workforce. Aust J Adv Nurs 24(4): 42-46

22. Ellis B, Rutter P, Greaves F, Noble D, Lemer C (2011) New models of clinical leadership: the Chief Medical Officer Clinical Advisor Scheme. Int J ClinLeadersh 17: 1-6.

23. Fuller P (2012) Program for developing leadership in pharmacy residents. Am J Health Syst Pharm 69(14): 1231-1233.

24. Leeson D, Millar M (2013) Using the 7 Habits programme to develop effective leadership. Nurs Manag (Harrow) 20(6): 31-37.

25. Gauld R (2014) Clinical governance development: learning from the New Zealand experience. Postgrad Med J 90: 43-47.

26. Psychogios AG, Priporas C (2007) Understanding total quality management in context: qualitative research on managers' awareness of TQM aspects in the Greek service industry. The Qualitative Report 12(1): 40-66.
27. Sadikoglu E, Zehir C (2010) Investigating the effects of innovation and employee performance on the relationship between total quality management practices and firm performance: an empirical study of Turkish firm. International Journal of Production Economics 127(1): 13-26.

28. Kima D, Kumarb V, Kumarb U (2012) Relationship between quality management practices and innovation. Journal of Operations Management 30(4): 295-315.

29. Khairul Anuar Mohd Ali, Main Naser Alolayyan (2013) The impact of total quality management (TQM) on the hospital's performance: an empirical research. Int J Services and Operations Management 15(4): 482-506.

30. Sartirana M, Noordegraaf M (2015) Opportunity does matter: supporting doctors in management. In: Pedersen A, Waldorff S, Ferlie E, Fitzgerald L, editors. Managing Change: From Health Policy to Practice. London: Palgrave.

31. Kirkpatrick I, Veronesi G, Zardini A (2016) Doctors in management: Challenging or reinforcing the professional status order? Naples: Paper presented at 31 EGOS Colloquium.

32. Borou A, Korakidi D, Sarakatsianou C, Matraki G, Matraki A, et al. (2013) Investigation of conflict management among nurses in public hospitals. Interscientific Health Care 5(3): 120-129.

33. Kalogeropoulou K, Papathanasopoulou E (2013) The impact of the economic crisis on the mental health of nurses: A pilot study. Archives of Hellenic Medicine 30(5): 587-594. 